\title{
¿Qué sentido tiene la crisis de la COVD-19?
}

Orientaciones para la búsqueda

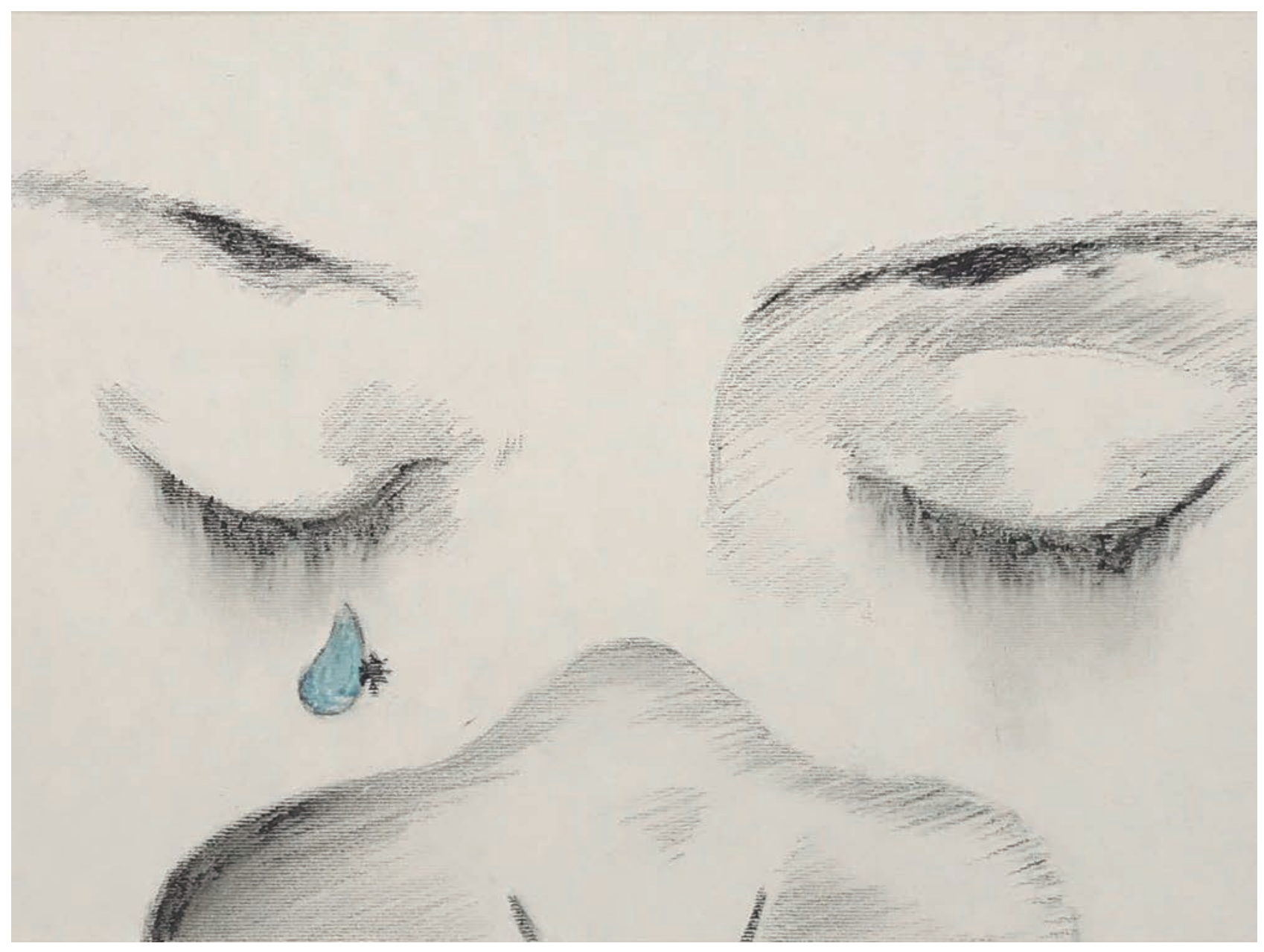

Momentos históricos, ya lo sabemos; estamos viviendo momentos históricos. Estamos viviendo momentos confusos, acelerados, con novedades importantes cada día. Pero además de lo excepcional, esta experiencia tiene características

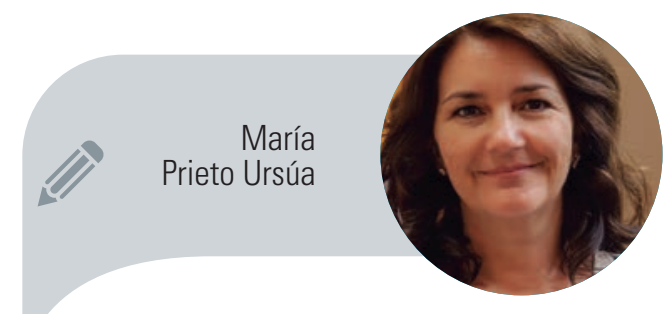
que la hacen especialmente traumática. 
Nos enfrentamos a un enemigo invisible que no conocemos bien aún, pero que puede arrebatarnos la salud e incluso la vida, la nuestra o la de los nuestros. Cada día nos muestra que es un enemigo poderoso, cada día cambia el escenario, sin casi tiempo para adaptarnos al anterior, sin casi tiempo para elaborar nuestros duelos. No es fácil acostumbrarse al miedo que produce la amenaza constante, la incertidumbre, lo desconocido. Nos asaltan las dudas y las preocupaciones: tenemos familiares que pasan el confinamiento en soledad, no podemos abrazarles, tocarles, consolarles... tenemos familiares o conocidos que forman parte de la población más vulnerable, que tienen otras enfermedades serias, tenemos serias dudas sobre si estamos haciendo lo correcto, personal y socialmente... muchas personas además tienen problemas económicos, han dejado de trabajar, no saben qué pasará con su futuro laboral... no sabemos a qué "normalidad" vamos a volver cuando volvamos a algún sitio

Pero, sobre todo, vivimos unos días sumidos en el dolor. Hace unas semanas que nuestras ciudades y pueblos han sido cubiertos con un manto de dolor y sufrimiento que nos encoge el corazón y nos Ilena el alma de piedras, aunque intentemos distraernos y ocupar nuestra mente en otras cosas. Los números son terribles, y detrás de cada número hay muchas historias de dolor por la pérdida, por la lucha y el fracaso, por la derrota, por la soledad, por la impotencia... Es uno de esos momentos en los que el ser humano se enfrenta al vacío de sentido, al absurdo, a la arbitrariedad, a la indefensión.

Pero precisamente por todo esto, por lo traumático y doloroso del momento, esta es una oportunidad privilegiada para que los adultos ayudemos a nuestros hijos, a nuestros alumnos, a dar un significado a esta experiencia. Podemos ayudarles a integrar lo vivido en su historia de forma que tenga un sentido, que los ayude a crecer y a madurar, que conserve e incluso mejore su forma ordenada de entender el mundo, la sociedad, las relaciones, los valores... El peor de los sufrimientos

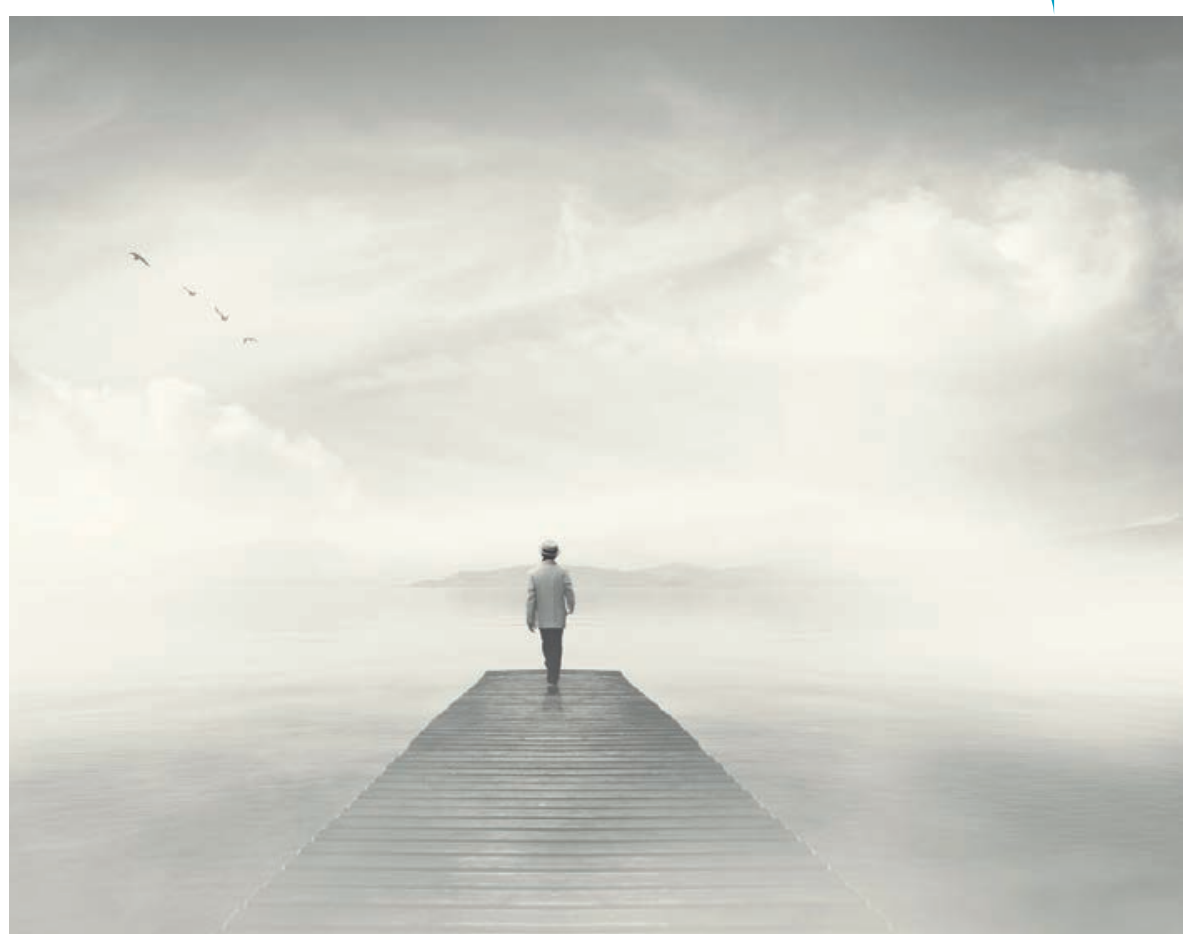

es el que se percibe como inútil, como arbitrario, desde el sinsentido. Pero no son las situaciones las que deciden el sentido, como vamos a ver.

Según Frankl, la motivación para encontrar un significado y un propósito en nuestra vida es la motivación fundamental de todo ser humano, que él llama voluntad de sentido. Gracias a ella, podemos encontrar una cierta experiencia de plenitud o madurez incluso en las situaciones más adversas. Vamos a profundizar en estos conceptos en los apartados siguientes.

\section{La amenaza del vacío existencial}

Es importante dejar un espacio en nuestra vida para la pregunta por el sentido de nuestra existencia, es importante tener momentos en los que tomar distancia de nuestra realidad inmediata y preguntarnos por nuestros objetivos, nuestras actuaciones, nuestro camino, 


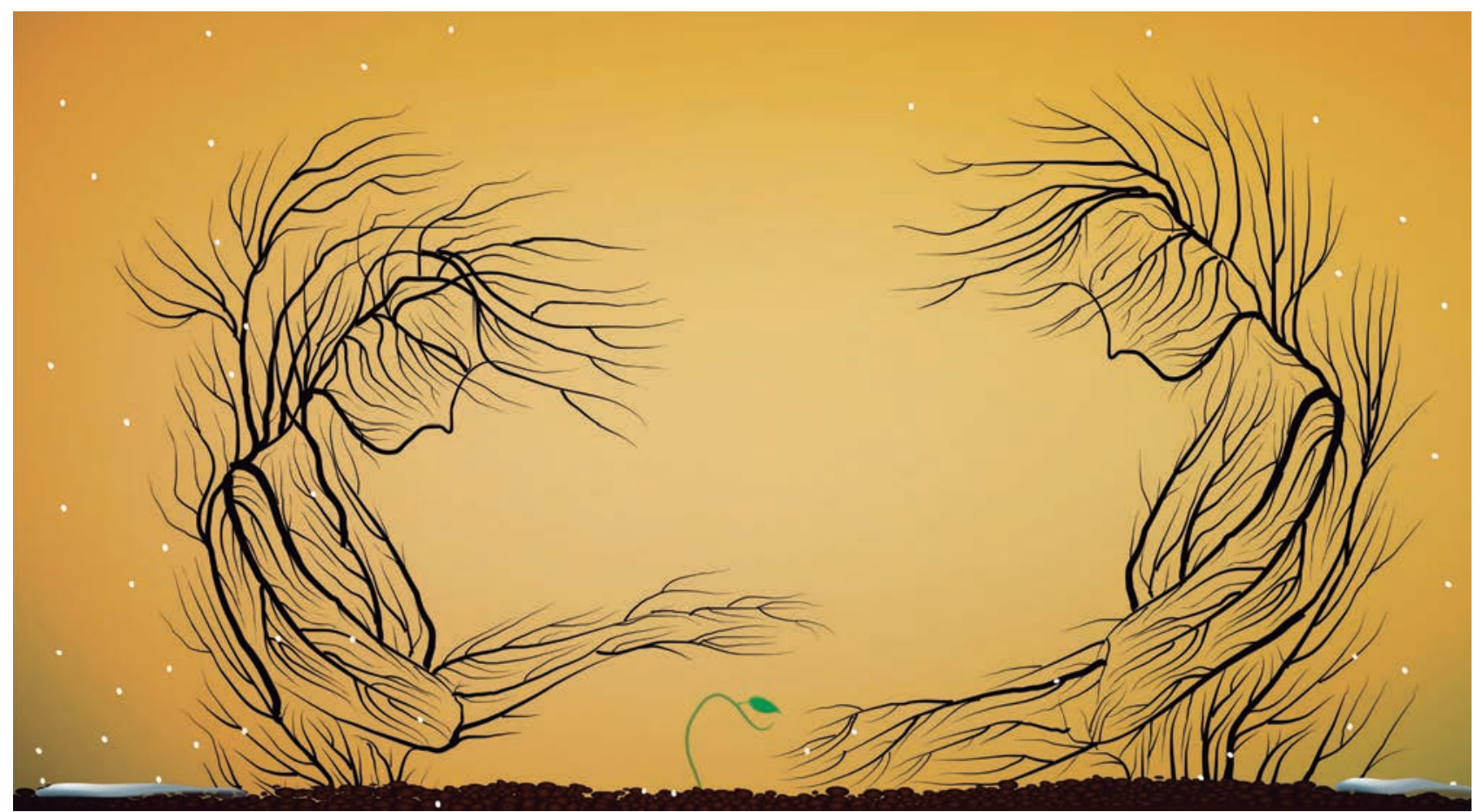

¿Cómo lo está haciendo? ¿Cómo puedo hacerle ver que me siento cuidado y agradecérselo?

2. Cuando me siento útil, cuando veo que ayudo a alguien, cuando colaboro al bien común. Los ejemplos de ayuda y colaboración al bien común son incontables en la sociedad estos días; estamos viendo cuidadores que se quedan voluntariamente confinados en sus trabajos con personas mayores, empresas que donan material sanitario, personas cosiendo mascarillas o imprimiendo viseras, accesos gratuitos a bienes y servicios (museos, revistas, libros...), tutoriales gratuitos sobre distintos contenidos (cocina, ejercicio físico, educación infantil, paternidad, manualidades ). Mirando en nuestro entorno inmediato, si en una familia estamos todos confinados es porque todos nos estamos cuidando mutuamente; si el número de nuevos casos ha frenado su escalada es porque nuestro confinamiento ha servido para no desbordar (más) los servicios sanitarios A veces cuesta entender que el "no hacer nada" es en realidad lo más heroico y activo que se puede hacer. Además, se puede haber contribuido de otras formas a que la situación sea mejor: ayudando a algún vecino, ocupándose de la casa o de la compra, dejando de alimentar o de difundir mensajes dañinos o desesperanzadores, ofreciendo consejos o tutoriales para enseñar a otros, dedicando muchas más horas de trabajo de las normales para mantener la calidad de nuestra docencia y cuidar a nuestros alumnos...

¿Cómo has intentado ayudar en esta situación? ¿Cómo has intentado que la situación sea algo mejor, más Ilevadera, para alguien? ¿Cómo te has sentido al hacerlo? ¿Cómo te sientes al ver la cantidad de acciones altruistas que muestra la sociedad estos días?

3. Cuando me siento comunidad, cuando me siento unido a otros. Hoy España está siendo un ejemplo grandioso de comunidad; las iniciativas de escucha y acompañamiento a los más vulnerables son ya incontables, las iniciativas de ayuda práctica a vecinos e incluso desconocidos también (compras, medicinas, clases particulares...), los aplausos de las 20h son algo más que una expresión de agradecimiento a los sanitarios y profesionales en primera línea: son una forma de sentirnos juntos y apoyados, una forma de hacer comunidad. En las redes sociales son numerosos los mensajes de 

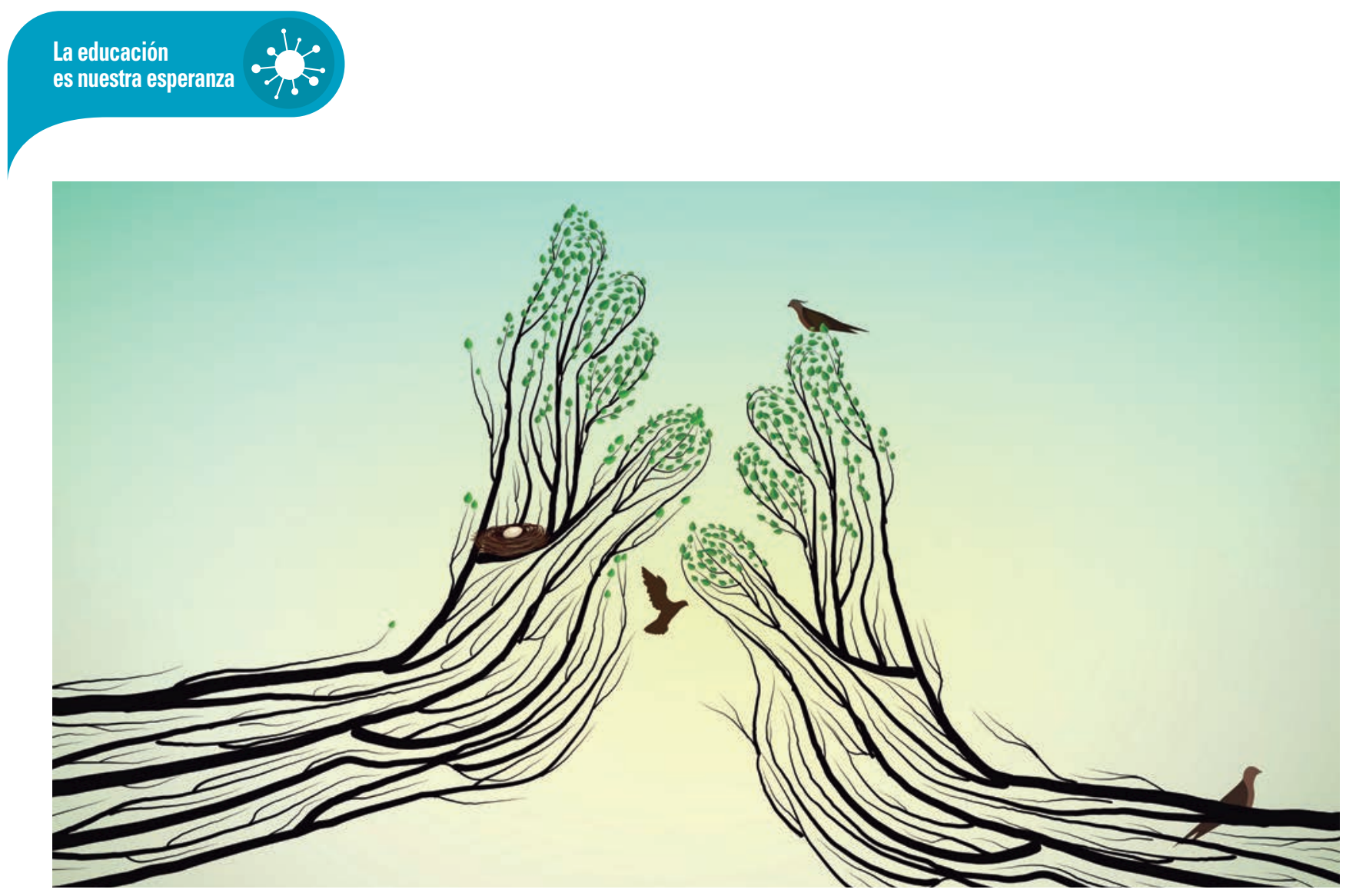

personas que simplemente quieren compartir su pérdida o expresar su dolor, mensajes que reciben cientos de respuestas de apoyo y ánimo de conocidos y desconocidos; en nuestro teléfono han aumentado las Ilamadas, los mensajes, las muestras de cariño y afecto a nuestros seres queridos, hemos aprendido a usar aplicaciones nuevas para vernos las caras y sentirnos más cerca. Sentirnos unidos a otros nos hace bien, somos seres sociales y nos necesitamos.

¿Hemos vivido alguna experiencia de comunidad estos días? ¿Nos hemos sentido formando parte de un grupo? ¿Cómo lo hemos vivido, cómo nos ha hecho sentir? ¿Cómo podríamos construir comunidad en nuestro entorno?

4. Cuando puedo actuar según mis valores o descubrir valores nuevos. Fuera de nuestras casas tenemos muchos ejemplos de personas que están mostrando los valores que viven, muchos ejemplos de generosidad y sacrificio; directivos y profesionales que se reducen el sueldo para mantener los puestos de trabajo, caseros que perdonan alquileres, hoteles que ceden sus instalaciones para lo que se necesite, artistas que donan sus derechos y beneficios para atender necesidades, voluntarios que reparten comida y consuelo a personas sin hogar, taxistas que trabajan gratis para llevar sanitarios, cocineros famosos que ofrecen comidas a los más necesitados, deportistas que subastan trofeos, empresas que se reinventan para fabricar productos necesarios, vecinos que comparten su talento con sus vecinos... de hecho, se ha detectado una "avalancha de generosidad" estas semanas. También vemos gestos de empatía y calidez, muestras de proximidad con enfermos y necesitados, cuando se aplaude y celebra cada alta, cuando se ayuda al enfermo a comunicarse con sus seres queridos, cuando se escriben cartas a los enfermos, a los mayores, cuando se les traslada gratis en coches de voluntarios...

¿Qué valores estás viendo y viviendo estos días? ¿Qué valores te ha sorprendido ver? ¿Qué valores te han estimulado, te han llenado de ilusión, te motivan y te animan a vivirlos tú también?

5. Cuando puedo crecer y madurar. Es grande el reto, la dificultad, el dolor. Es grande la crisis. España se está llevando la peor parte, por las razones que sean. Y aquí estamos, aguantan- 
do, apretando músculos y soportando la sacudida, firmes en nuestro confinamiento, constantes, sabiendo que cuando todo pase, el panorama va a ser desolador, como ya estamos empezando a ver. Y saldremos, como sociedad, como personas, y podremos reconstruirnos, y lo intentaremos hacer mejor. Por las redes circulan artículos, tuits, mensajes, entrevistas... que anticipan que, en el terreno personal, vamos a salir distintos de nuestro confinamiento; que vamos a salir mejores, más conscientes, más fuertes. Yo no creo que el confinamiento nos vaya a afectar a todos por igual; no éramos todos iguales antes de empezar, y no lo vamos a ser después. En concreto, al final de estas semanas podremos encontrar personas que saldrán de esta crisis igual que han entrado: habrán dedicado los días y las horas a distraerse, a no pensar, a entretenerse, a llenarse de estímulos, a moverse en la misma superficialidad de siempre. Para aprovechar lo vivido de forma que nos ayude a crecer y madurar necesitamos parar y mirarnos, y preguntarnos:

¿He cambiado en algo en esta situación? ¿He aprendido algo de mí que no supiera? ¿Me ha gustado algo especialmente? ¿Hay algo que quiera potenciar en el futuro? ¿Algo que me gustaría corregir o cambiar?

6. Cuando me siento libre y capaz de decidir, de aceptar la situación. Esta es una de las claves importantes del sentido: la experiencia de que no son las situaciones las que deciden cómo me siento o cómo actúo, la experiencia de libertad, de que puedo seguir controlando mi vida incluso cuando no puedo controlar nada de las circunstancias que me rodean. Yo elijo muchas cosas cada día, empezando por la actitud con la que me voy a enfrentar a él, en qué datos fijarme, qué discurso hacer, qué hago con mi tiempo. Las circunstancias nos lo ponen más o menos difícil, ayudan más o menos, pero el ser

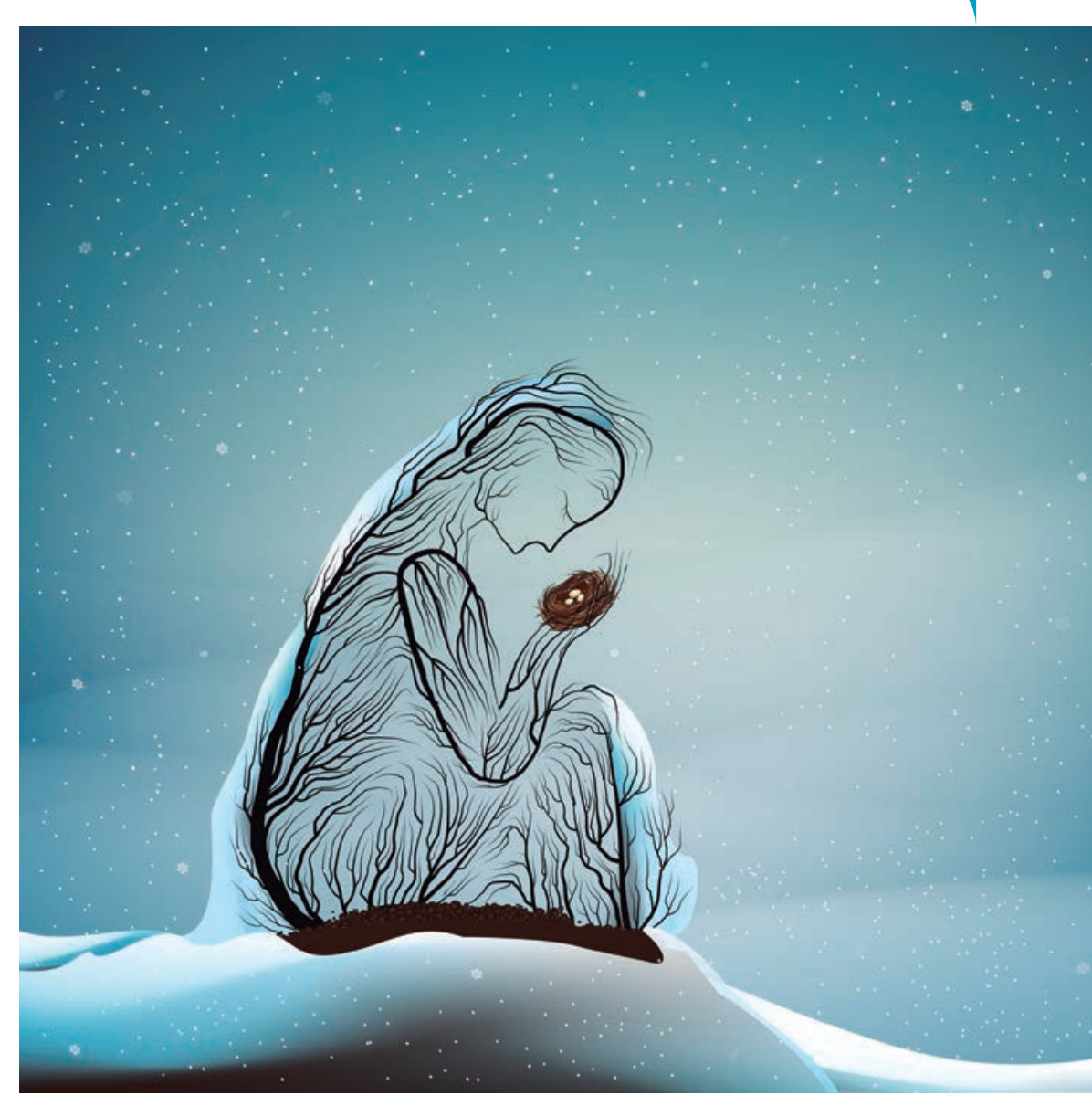

humano es mucho mayor, mucho más fuerte que lo que dictan las circunstancias. Recordemos el final del precioso poema de William Ernest Henley:

[...]

Más allá de este lugar de cólera y lágrimas donde yace el Horror de la Sombra, la amenaza de los años me encuentra, y me encontrará, sin miedo.

No importa cuán estrecho sea el portal, cuán cargada de castigos la sentencia,

soy el amo de mi destino: soy el capitán de mi alma.

\begin{abstract}
¿Me siento capaz de controlar mi actitud, a pesar de la situación? ¿Qué me ayuda a sentirme "capitán de mi alma"? ¿Qué-quién me ha ayudado en estos días a sentirme libre en medio del confinamiento?
\end{abstract}

\section{Las fuentes de sentido último}

Más allá del sentido provisional, más allá de la pregunta por el sentido en cada instante de la vida, nos estamos planteando la pregunta por el significado último. Para encontrarlo, es imprescindible un 


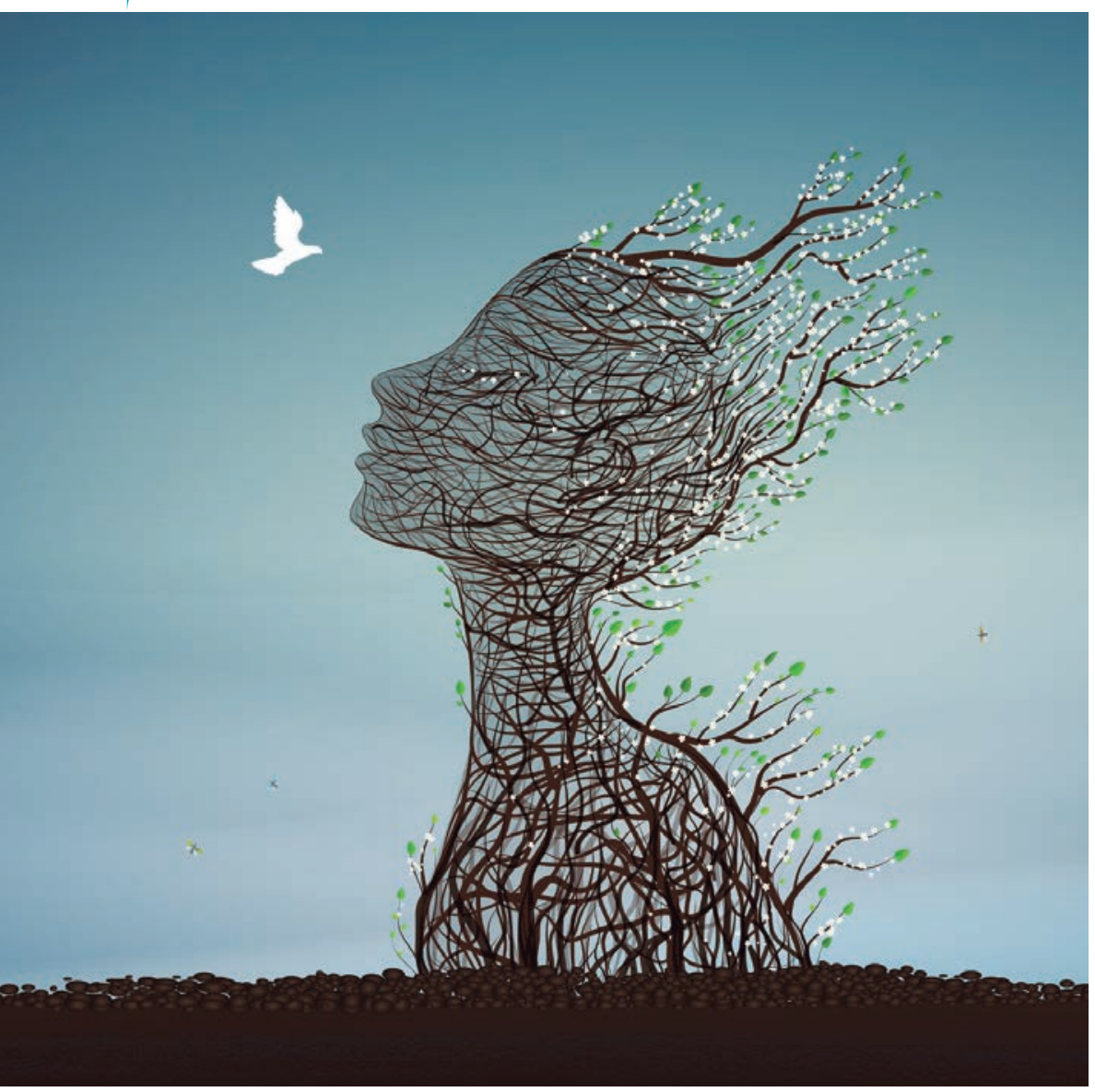

cierto distanciamiento del aquí y el ahora, es necesario alejarnos de la situación concreta para ponerla en contexto y mirarla con perspectiva; y después, en ese lugar privilegiado desde donde mirarnos con distancia, preguntarnos por el significado y por la respuesta a las grandes preguntas.

Una experiencia tiene sentido último cuando cambia o mejora mi visión o el significado que doy a esas preguntas: la vida y la muerte, el concepto de sociedad actual, la naturaleza humana, nuestra re-

\section{DARA SABER MÂS}

FrankL, V. E. (1983, $1^{a}$ ed. 1946). El hombre en busca del sentido último. Barcelona: Herder.

Boné, I. (2019). Vulnerabilidad: condición humana abierta al abrazo y la disposición. En R. Meana (Dir.), El sujeto. Reflexiones para una antropología ignaciana (pp. 409434). Bilbao: Mensajero-Sal Terrae-Universidad Comillas. lación con la naturaleza, la necesidad de trascendencia...

Este número de la revista es una ayuda valiosísima para ayudarnos a encontrar el sentido último de esta crisis, y también lo son tantas entrevistas y artículos que estos días nos ayudan a reflexionar. Quizás hemos repensado y revalorado, por ejemplo, el valor del contacto y la relación directa, la importancia del abrazo y de la presencia, o hemos imaginado posibles futuros distintos (en lo económico, en las formas de trabajar...), hemos redescubierto la importancia de la solidaridad, o el peligro del miedo y los comportamientos insolidarios que se derivan de él, o, finalmente, nos hemos reconciliado con la muerte, incluso con la muerte sin compañía ni ritos, y hemos aprendido a vivir los ritos pendientes en paz, esperando a que llegue el momento de la elaboración serena de la pérdida.

Es también este un momento especial para abrazar nuestra vulnerabilidad, apreciar tanto nuestra pequeñez como nuestra grandeza, y asombrarnos de nuestra preciosa y contradictoria naturaleza humana. Somos muy poca cosa y, a la vez, somos fuertes, capaces de soportar y trascender pandemias y virus.

Espero que estas líneas nos hayan ayudado a encontrar alguna respuesta, pero, sobre todo, espero que nos hayan ayudado a hacernos preguntas y, espero que, después de encontrar nuestras respuestas, sigamos haciéndonos más preguntas. Ese es el camino para encontrar el sentido •

HEMOS HABLADO DE

\section{Sentido de la vida; crecimiento postraumático; vulnerabilidad; crisis; madurez.}

Este artículo fue solicitado por PADRES Y MAESTROS en marzo de 2020, revisado y aceptado en mayo de 2020 . 